Research Paper

\title{
Circulating microRNA profiles in plasma: identification of miR-224 as a novel diagnostic biomarker in hepatocellular carcinoma independent of hepatic function
}

\author{
Wataru Okajima ${ }^{1, *}$, Shuhei Komatsu ${ }^{1, *}$, Daisuke Ichikawa ${ }^{1}$, Mahito Miyamae ${ }^{1}$, \\ Tsutomu Kawaguchi ${ }^{1}$, Shoji Hirajima ${ }^{1}$, Takuma Ohashi $^{1}$, Taisuke Imamura ${ }^{1}$, Jun \\ Kiuchi $^{1}$, Tomohiro Arita ${ }^{1}$, Hirotaka Konishi ${ }^{1}$, Atsushi Shiozaki ${ }^{1}$, Ryo Moriumura ${ }^{1}$, \\ Hisashi Ikoma', Kazuma Okamoto', Hiroki Taniguchi' ${ }^{2}$, Yoshito Itoh ${ }^{3}$, Eigo Otsuji ${ }^{1}$ \\ ${ }^{1}$ Division of Digestive Surgery, Department of Surgery, Kyoto Prefectural University of Medicine, Kawaramachihirokoji, \\ Kamigyo-ku, Kyoto, 602-8566, Japan \\ ${ }^{2}$ Department of Surgery, Kyoto Second Red Cross Hospital, Haruobicho, Kamigyo-ku, 602-8026, Kyoto, Japan \\ ${ }^{3}$ Department of Molecular Gastroenterology and Hepatology, Kyoto Prefectural University of Medicine, Kawaramachihirokoji, \\ Kamigyo-ku, Kyoto, 602-8566, Japan \\ "These authors contributed equally to this work \\ Correspondence to: Shuhei Komatsu, email: skomatsu@koto.kpu-m.ac.jp \\ Keywords: plasma, circulating microRNA, liquid biopsy, liver cirrhosis, tumor marker \\ Received: February 17, $2016 \quad$ Accepted: July 09, $2016 \quad$ Published: July 22, 2016
}

\section{ABSTRACT}

Aims: This study was designed to identify novel microRNAs (miRNAs) in plasma for detecting and monitoring hepatocellular carcinoma (HCC), independent of hepatic function and background liver diseases with different etiologies.

Results: (1) Four oncogenic miRNAs (miR-151, 155, 191 and 224) with high expression in HCC tissues were selected as candidates. (2) Quantitative RT-PCR using plasma samples from $107 \mathrm{HCC}$ patients and 75 healthy volunteers revealed a significantly higher level of plasma miR-224 in HCC patients than in healthy volunteers according to a small-scale analysis $(P<0.0001)$, two independent large-scale cohort analysis ( $P<0.0001$, AUC 0.908). (3) miR-224 expression was significantly higher in HCC tissues and HCC cell lines than in normal hepatic tissues and fibroblasts, respectively. ( $P=0.0011,0.0150)(4)$ Plasma miR-224 reflected tumor dynamics; preoperative plasma levels of miR-224 were significantly reduced in postoperative samples $(P=0.0058)$, and plasma miR-224 levels were significantly correlated with paired miR-224 levels in HCC tissues $(P=0.0005)$. (5) Furthermore, plasma miR224 levels significantly discriminated HCC patients from patients with chronic liver disease $(P=0.0008)$. A high plasma miR-224 level was significantly correlated with larger tumor size $(P=0.0005)$ and recurrences $(P=0.0027)$. The plasma miR-224 level could accurately detect small tumors less than $18 \mathrm{~mm}$ preoperatively.

Methods: We performed a systematic review of the NCBI database and selected candidate miRNAs reported as highly expressed in HCC tissue.

Conclusions: Plasma miR-224 may be a sensitive biomarker for screening HCC and monitoring tumor dynamics.

\section{INTRODUCTION}

Hepatocellular carcinoma (HCC) is the second most common cause of cancer deaths worldwide. Despite continuous global efforts aimed at eradication and improvements in various treatment techniques, the prognosis of $\mathrm{HCC}$ remains poor. Even in major advanced economies, the mortality rates have been increasing [1]. Although HCC is a typical viral infection-related malignancy derived from chronic hepatitis B and C [2-3], HCC has also been strongly associated with lifestyle. Excessive alcohol consumption, obesity and type 2 
diabetes are strongly associated with the carcinogenesis and development of HCC [4-7]. Thus, not only the proportion but also the number of HCC patients with nonviral etiologies has been increasing on a global scale [2].

Because identifying clinical biomarkers and molecular targets for HCC may contribute to improving the survival rate of patients with this lethal disease, several recent studies have clarified that certain molecules and associated signaling pathways, such as Ras/Raf/MAPK, PI3K/Akt/mTOR, Wnt- $\beta$-catenin, Hedgehog, HGF/c-Met and EGFR, have important roles in hepatocarcinogenesis [8-13]. In clinical settings, however, few molecules have been validated as diagnostic, therapeutic and/or prognostic biomarkers for HCC. Alpha-fetoprotein (AFP), AFP lectin fraction (AFP-L3) and proteins induced through vitamin $\mathrm{K}$ deficiency or antagonist-II (PIVKA-II), which is also known as des- $\gamma$-carboxy prothrombin (DCP), have been used as conventional serum tumor markers. These markers, however, lack sufficient sensitivity and specificity [14-16]. Hence, the use of less invasive technology for the development of novel molecular biomarkers for HCC, independent of background liver function and diseases with different etiologies, is needed and might facilitate the detection of early stage $\mathrm{HCC}$ and monitoring of tumor dynamics.

MicroRNAs (miRNAs), small non-coding RNAs that regulate the translation of specific protein-coding genes, were discovered in 1993 [17]. Since then, miRNAs have been intensively studied in cancer science. The altered expression of miRNAs has been associated with several diseases and implicated in the development of various cancers [18-21]. Recently, several studies have detected miRNAs in the plasma/serum in a remarkably stable form [19, 22-25]. Tumor-derived miRNAs are resistant to endogenous ribonuclease activity in plasma/ serum, as these molecules bind to certain proteins, such as the Argonaute 2 protein and high-density lipoproteins [26-27], or are packaged into secretory vesicles, including apoptotic bodies and exosomes in plasma/serum [22, 28-30]. The expression of each miRNA in the blood is consistent in all healthy individuals [22-23]. Furthermore, secretory vesicles, containing specific miRNAs, function as intercellular transmitters; secreted miRNAs from donor cells can be transferred to and function in recipient cells [31-33]. These findings have prompted the identification of novel liquid biomarkers of miRNAs in cancers. We have previously identified cancer-associated miRNAs in plasma, which might be useful for the detection of cancer, monitoring of tumors, prediction of malignant potential, and prognosis and chemoresistance in gastric, esophageal and pancreatic cancers [25, 34-44].

Concerning plasma/serum miRNAs in HCC, several research groups have reported the potential utility of miRNAs circulating in plasma/serum in clinical applications [45-47]. However, these miRNAs are not necessarily candidates for $\mathrm{HCC}$, and more sensitive and promising candidates for the early detection and treatment of HCC, independent of background liver diseases and liver function, are needed in clinical settings. Therefore, the aim of the present study was to identify novel plasma miRNA candidates using a genome-wide database approach.

In this study, we conducted a systematic review of the NCBI database and compared the plasma levels of four candidate miRNAs (miR-151, 155, 191 and 224) with an oncogenic function, reported as highly expressed in HCC tissue, between HCC patients and healthy volunteers. We ultimately validated plasma miR-224 as a useful biomarker for screening HCC, monitoring tumor dynamics and evaluating tumor residue following non-surgical treatment. Our results provide evidence that the plasma level of miR-224 meaningfully contributes to clinical decision-making.

\section{RESULTS}

\section{Study design to find novel plasma miRNA biomarkers for HCC}

The present study was designed according to the following scheme: (1) Selection of appropriate miRNA candidates based on a systematic review of the NCBI database (Figure 1B and Supplementary Table S1); (2) Small-scale analysis of the plasma samples using qRT-PCR to validate the utility of the selected miRNA candidates (Figure 2 and Supplementary Figure S1); (3) Confirmation of higher miR-224 expression in primary HCC tissues and HCC cell lines (Figure 3A and 3B); (4) Large-scale analysis to validate the plasma level of miR-224 (Figure 3C) and two independent-cohorts analyses (Supplementary Figure S2); (5) Evaluation of the clinicopathological features related to plasma miR-224 level (Table 1 and Supplementary Table S2); (6) Evaluation of whether the plasma miR-224 expression levels reflect tumor dynamics (Figure 3D and 3E); (7) Evaluation of whether the plasma miR-224 expression in peripheral blood could be a diagnostic biomarker independent of hepatic function (Figure 5A, 5B, 5C, Figure 6 and Supplementary Figure $\mathrm{S} 3 \mathrm{~B}$ ); and (8) Evaluation of whether the plasma miR-224 expression level could be an indicator of clinical outcome (Figure 7A and 7B); revealing that (9) plasma miR-224 is a novel candidate for HCC screening, monitoring, and evaluating treatment outcome.

\section{Selection of candidate miRNAs from the NCBI database}

Using a systematic review of the NCBI database, we selected candidate miRNAs. Figure 1B shows a detailed description of the selection process. A total of 281 relevant full articles related to HCC were retrieved from PubMed up to February 2013. From these reports, we selected 124 
candidate miRNAs as shown in Supplementary Table S1. The detailed selection criteria for the candidate miRNAs are described in the Materials and Methods. To identify more sensitive and reliable biomarkers, we focused on miRNAs whose expression levels had been previously validated in HCC tissues. Consequently, 34 miRNAs were excluded. Next, 11 miRNAs previously reported as biomarkers in body fluids were excluded. We limited the target miRNAs to oncogenic miRNAs, as previous studies have revealed that high plasma levels of oncogenic miRNAs might be derived from tumor necrosis, apoptosis and the active release of secretory vesicles, such as exosomes, from cancer cells; thus, these miRNAs in plasma could reflect tumor dynamics in cancer tissues [34-35, 40-41]. Tumorsuppressive miRNAs and functionally unknown miRNAs were excluded in the present study because the origin of these miRNAs is not well known [38]. Consequently, 48 miRNAs were excluded. Furthermore, 27 miRNAs, insufficient for clinical application and reported in only one article, were excluded. After a series of exclusion criteria were applied, we systematically selected four candidate miRNAs: miR-151 [48-49], miR-155 [50-51], miR-191 [52-53], and miR-224 [54-58].

A

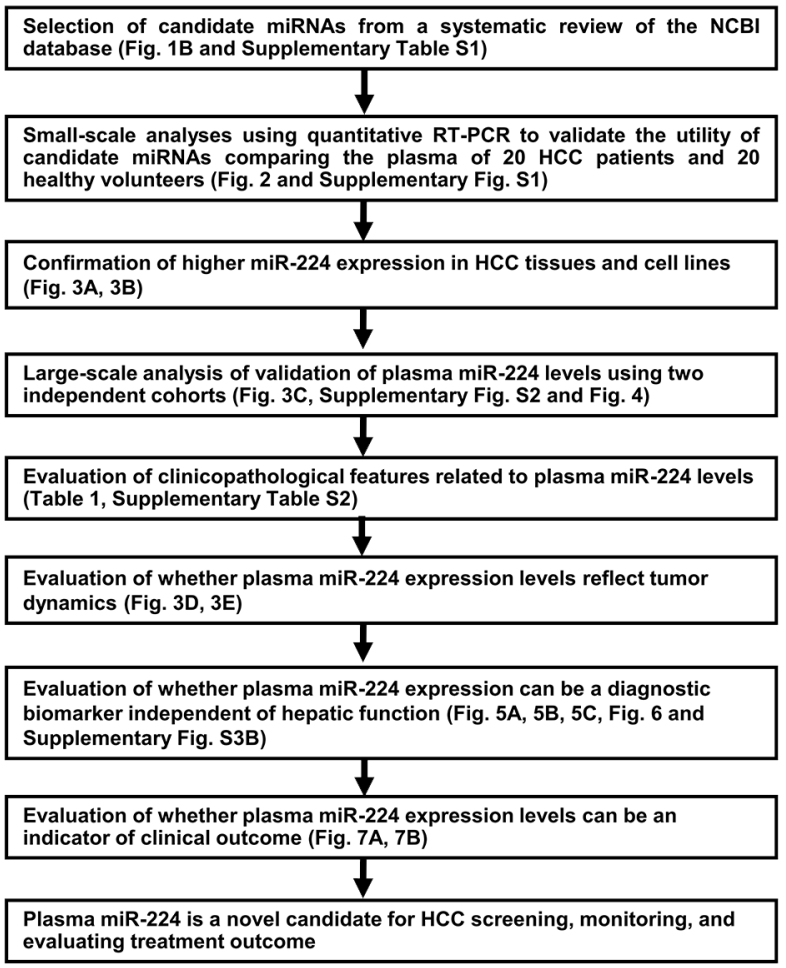

\section{Small-scale analysis of the plasma levels of four candidate miRNAs in HCC patients and healthy volunteers}

We next investigated the plasma levels of the four miRNAs in 20 consecutive HCC patients and 20 healthy volunteers using qRT-PCR as a small-scale analysis. Regarding this cohort, the proportion of background hepatic disease was categorized as $40 \%$ of HCC patients with non-B, non-C and $60 \%$ of $\mathrm{HCC}$ patients with viral etiology. The plasma levels of all candidate miRNAs were significantly higher in HCC patients than in healthy volunteers, the plasma miR224 level was validated to exhibit the most significant difference (Figure 2). Moreover, the plasma levels of miRNA-151 and miRNA-191 were significantly higher in the plasma of HCC patients with hepatitis B or C than in non-B, non-C patients. Therefore, we excluded these two miRNAs from the candidate miRNAs to select candidates independent of background liver disease with different etiologies (Supplementary Figure $\mathrm{S} 1)$. Furthermore, we utilized the area under the ROC curve using the Youden index and calculated the value

B

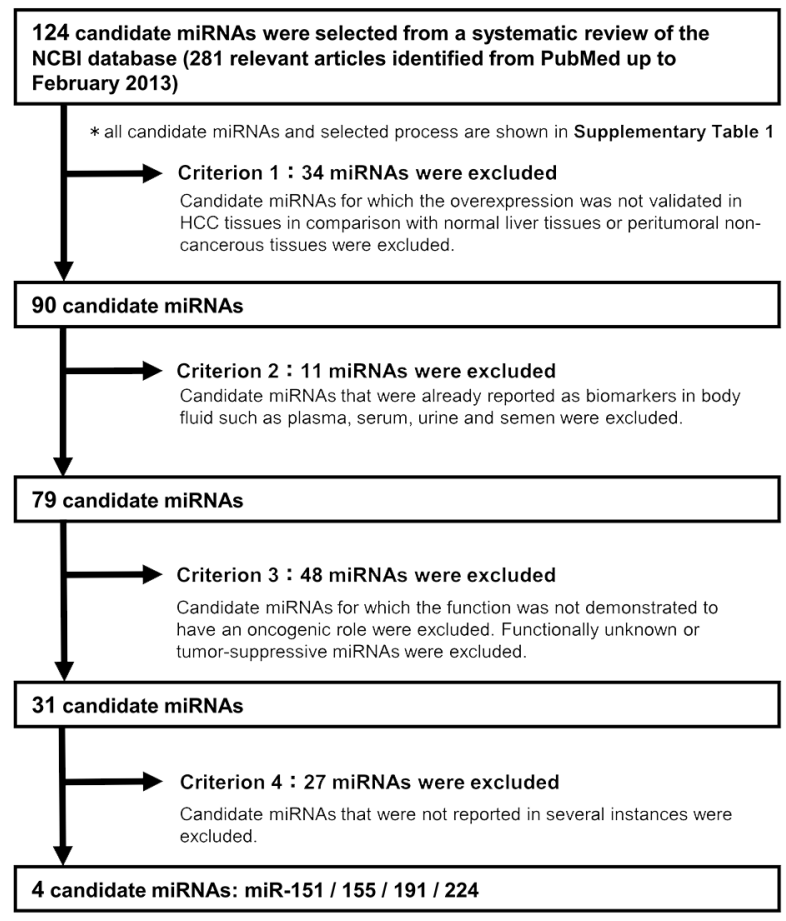

Figure 1: A. Selection of the candidate microRNAs from the NCBI database. B. Study design to identify novel plasma miRNA biomarkers for HCC. Using a systematic review of the NCBI database, we selected four candidate miRNAs for cancer detection and monitoring. Candidate miRNAs, previously reported to have an oncogenic role in HCC and previously confirmed in tissues or cell lines but not in body fluids, were selected. Among these, the expression level of plasma miR-224 showed the most significant difference $(\mathrm{P}<0.0001)$. Thus, further analyses of plasma miR-224 were conducted. 
for the AUC for miR-155 and miR-224 [59]. The AUC value for the plasma miR-155 and miR-224 were 0.589 and 0.905 , respectively. Thus, we selected the most promising candidate, miR-224, for further analyses.

\section{Confirmation of higher miR-224 expression in HCC tissues and cell lines}

Next, we confirmed the expression level of miR224 in primary HCC tissues and HCC cell lines compared with normal tissues and the fibroblast cell line WI-38. We used qRT-PCR to determine the expression of miR-224 in paired 12 normal hepatic tissues (Figure 3A) and in the human HCC cell lines, such as JHH, HLE, Hep-G2 and Alexander cells (Figure 3B). The miR-224 expression level was significantly higher in HCC tissues than in normal hepatic tissues $(\mathrm{P}=0.0011)$ (Figure $3 \mathrm{~A})$. The expression of miR-224 was significantly higher in the HCC cell lines than in normal hepatic tissues and the fibroblast cell line WI-38 ( $\mathrm{P}=0.0150)$ (Figure 3B). These findings strongly suggested that miR-224 expression was highly expressed in $\mathrm{HCC}$, as shown in previous reports [54-58].
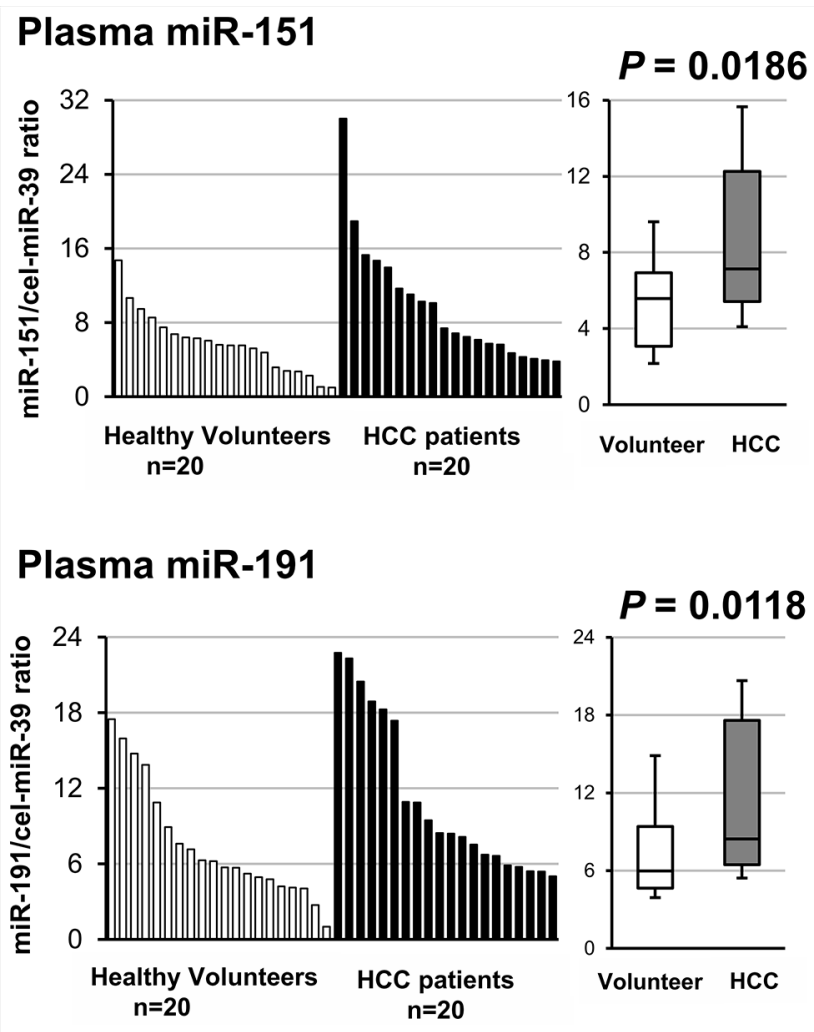

\section{Large-scale analysis of the miR-224 plasma levels in HCC patients}

We next validated these observations in large-scale settings. Prior to the analysis of a large number of samples using qRT-PCR, the linearity of qRT-PCR was confirmed using various concentrations of $1 \mathrm{fmol}$ to $0.0001 \mathrm{fmol}$ of each synthetic miRNA, namely, miR-224 $\left(\mathrm{R}^{2}=0.9981\right)$ and cel-miR-39 $\left(\mathrm{R}^{2}=0.9977\right)$, between the logarithm of the amount of input miRNA and Ct values (Supplementary Figure S3A). Recent reports have demonstrated that some circulating miRNAs might be derived from peripheral blood cells [60]. In the present study, there was no significant correlation between the plasma miR-224 level and the number of any type of peripheral blood cell (Supplementary Figure S3B).

Plasma miR-224 was detected in all samples from the $87 \mathrm{HCC}$ patients and 55 healthy volunteers. Using large validation cohorts, we showed that the plasma level of miR-224 was significantly higher in the HCC patients than in the healthy volunteers $(\mathrm{P}<0.0001)$ (Figure $3 \mathrm{C})$. Furthermore, to detect any cut-off points differentiating cancer patients from healthy volunteers, we utilized the

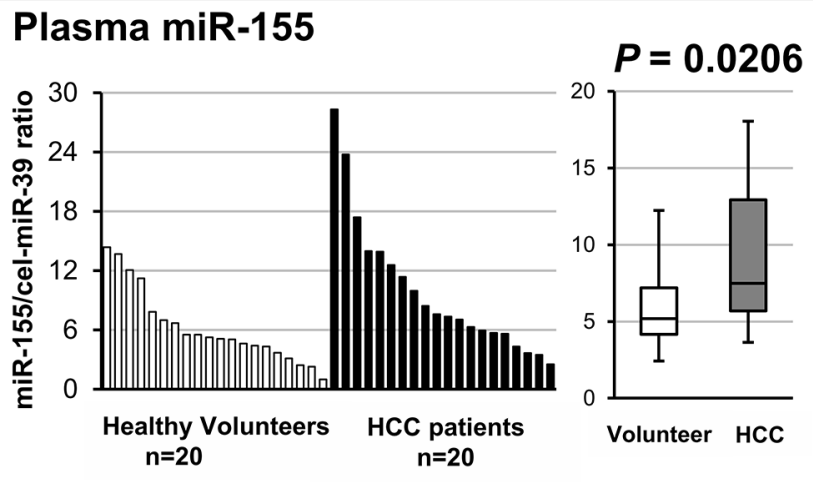

\section{Plasma miR-224}

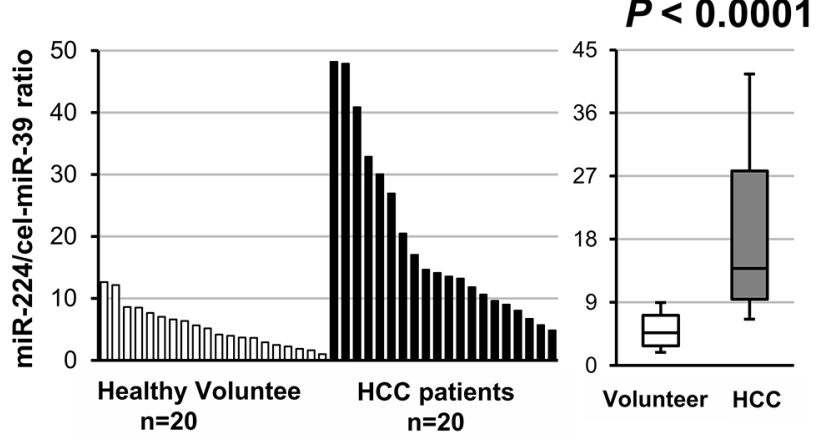

Figure 2: Small-scale analyses comparing the plasma levels of four candidate miRNAs between HCC patients and healthy volunteers. Plasma levels of the four candidate miRNAs in $20 \mathrm{HCC}$ patients and 20 healthy volunteers were analyzed using qRTPCR. The expression level of each miRNA was normalized to that of cel-miR-39 as described in the Materials and Methods. All candidate miRNAs showed significantly higher expression levels in HCC patients than in healthy volunteers. Among these, the expression level of plasma miR-224 showed the most significant difference $(\mathrm{P}<0.0001)$. 
area under the ROC curve using the Youden index [59] and calculated the value for the AUC of the validation cohort. The AUC value for the plasma miR-224 analysis was 0.908 . The optimal cut-off point was 8.0 in relative expression using the miR-224/cel-miR-39 ratio with a sensitivity of $93.1 \%$, a specificity of $80.0 \%$, and an accuracy of $88.0 \%$.

Because the validation cohorts comprised samples from two independent institutes, we also examined variations using two independent cohorts. The results were nearly identical in each independent cohort (Supplementary Figure S2). In the two independent cohorts, the miR-224 plasma level was significantly higher in the $\mathrm{HCC}$ patients than in the healthy volunteers $(\mathrm{P}<0.0001)$. Additionally, the AUC values for the plasma miR-224 analysis were 0.914 and 0.906, respectively. In the first cohort, the cut-off point was 8.0 in relative expression using the miR-224/cel-miR-39 ratio with a sensitivity of $87.7 \%$, a specificity of $86.3 \%$, and an accuracy of $88.5 \%$. In second cohort, the cut-off point was 8.0 in relative expression using the miR-224/celmiR-39 ratio with a sensitivity of $87.7 \%$, a specificity of $86.3 \%$, and an accuracy of $87.2 \%$. Similar to the smallscale analysis, the consistency of the results using largescale validation cohorts and two independent cohorts provided strong evidence that the plasma miR-224 level could satisfactorily distinguish HCC patients from healthy volunteers compared with conventional tumor markers.

Furthermore, to demonstrate the clinical utility, we next compared the plasma miR-224 levels between early stage HCC patients and the healthy volunteers in the validation cohort. We defined stage I HCC as early stage $\mathrm{HCC}$, according to the two staging systems such as the LCSGJ and TNM (AJCC/UICC). The results were almost same in both staging systems, namely, the miR-224 plasma level was significantly higher in stage I HCC patients than in the healthy volunteers $(\mathrm{P}<0.0001)$. The AUC values in the LCSGJ and TNM (AJCC/UICC) staging systems
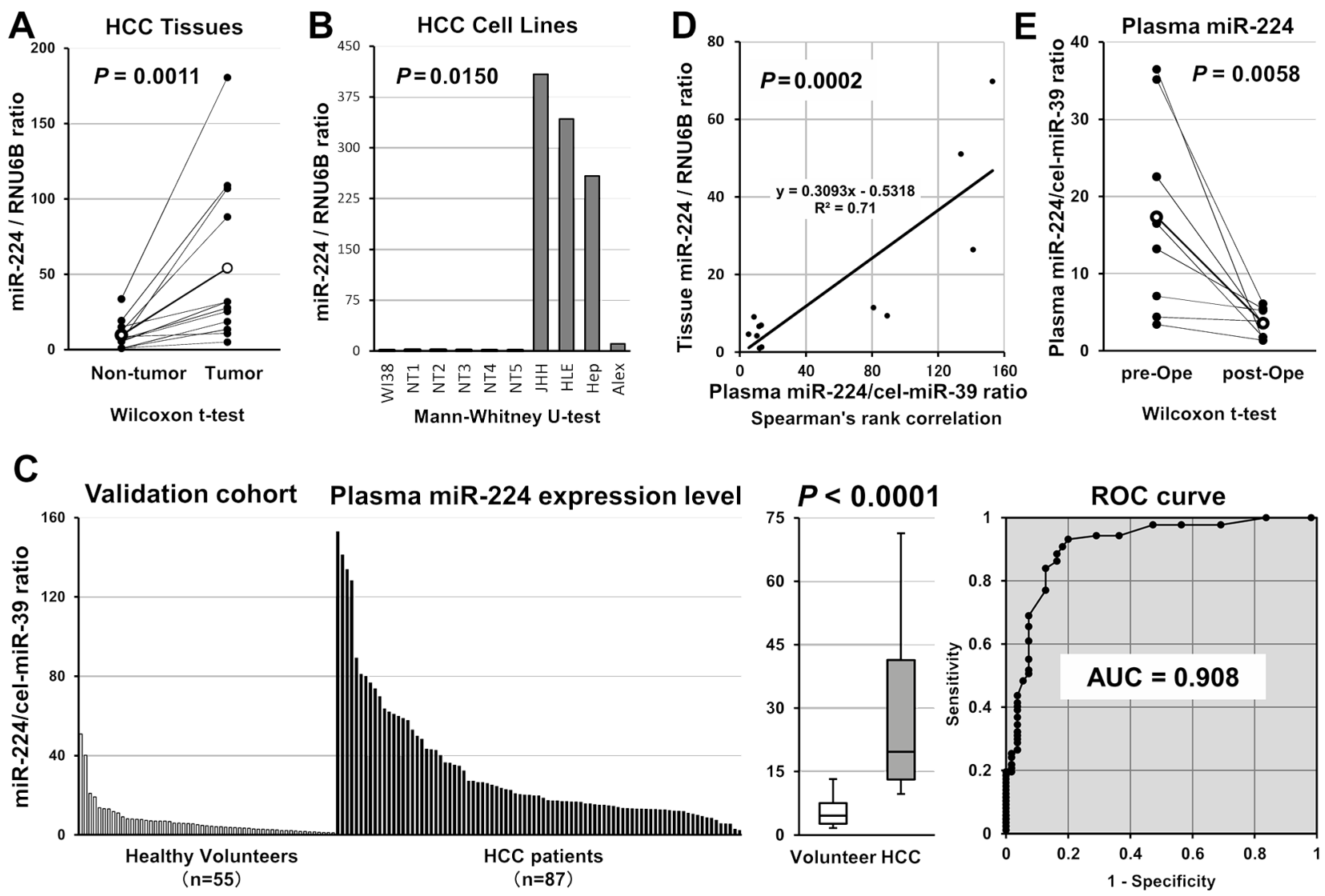

Figure 3: A, B. Confirmation of the expression level of miR-224 in HCC tissues and HCC cell lines. miR-224 expression was significantly higher in HCC tissues $(\mathrm{P}=0.0011)$ and HCC cell lines $(\mathrm{P}=0.0150)$ than in normal tissues and fibroblasts, respectively. C. Large-scale analysis of the plasma level of miR-224 in HCC patients using a validation cohort. The expression level of plasma miR-224 was significantly higher in HCC patients than in healthy volunteers $(\mathrm{P}<0.0001)$, and this finding was validated in large-scale analysis $($ AUC was 0.908$)$. For the large-scale analysis, total RNA extracted from plasma samples obtained from 87 HCC patients and 55 age-matched healthy volunteers were used to analyze the expression level of miR-224 using qRT-PCR. D. The correlation between the plasma and the tissue levels of miR224 were confirmed in HCC patients using paired samples $(\mathrm{P}=0.0005)$. E. Evaluation of whether the plasma miR-224 levels reflect tumor dynamics. The expression level of miR-224 was significantly reduced in postoperative plasma samples $(\mathrm{P}=0.0058)$. 
Table 1: Association between plasma miR-224 level and clinicopathological characteristics in patients with HCC

\begin{tabular}{|c|c|c|c|c|}
\hline \multirow[t]{2}{*}{ Variables } & & \multirow[t]{2}{*}{$\mathbf{n}$} & \multicolumn{2}{|c|}{ Plasma miR-224 } \\
\hline & & & Median & $P$ value \\
\hline Total & & 87 & 19.69 & \\
\hline \multirow[t]{2}{*}{ Gender } & male & 59 & 17.02 & 0.1396 \\
\hline & female & 28 & 23.60 & \\
\hline \multirow[t]{2}{*}{ Age (years old) } & $<70$ & 32 & 17.23 & 0.3963 \\
\hline & $70 \leq$ & 55 & 19.69 & \\
\hline \multirow[t]{2}{*}{$\mathrm{BMI}^{\mathrm{b}}$} & $<25$ & 60 & 20.27 & 0.1364 \\
\hline & $25 \leq$ & 27 & 14.99 & \\
\hline \multirow[t]{2}{*}{$\mathrm{DM}^{\mathrm{c}}$} & Positive & 25 & 17.22 & 0.2225 \\
\hline & Negative & 62 & 19.69 & \\
\hline \multirow[t]{2}{*}{ Viral infection (HBV or HCV) } & Positive & 52 & 21.90 & 0.1207 \\
\hline & Negative & 35 & 16.82 & \\
\hline \multirow[t]{2}{*}{ Liver cirrhosis } & Positive & 28 & 20.46 & 0.3848 \\
\hline & Negative & 59 & 17.32 & \\
\hline \multirow[t]{2}{*}{ Pathological Type } & Well $^{\mathrm{d}}$ & 23 & 16.82 & 0.3519 \\
\hline & Moderately or poorly ${ }^{\mathrm{e}}$ & 64 & 19.85 & \\
\hline \multirow[t]{2}{*}{ Vascular invasion } & Positive & 14 & 16.90 & 0.4499 \\
\hline & Negative & 73 & 19.69 & \\
\hline \multirow[t]{2}{*}{ Tumor size (mm) } & $<20$ & 35 & 14.99 & 0.0005 \\
\hline & $20 \leq$ & 52 & 24.02 & \\
\hline \multirow[t]{2}{*}{ pStage $\left(\right.$ LCSGJ $\left.{ }^{f}\right)$} & I & 30 & 15.36 & 0.0382 \\
\hline & II-IV & 57 & 20.34 & \\
\hline \multirow[t]{2}{*}{ pStage (TNM: AJCC/UICC $\left.{ }^{g}\right)$} & I & 62 & 19.85 & 0.4464 \\
\hline & II-IV & 25 & 17.16 & \\
\hline \multirow[t]{2}{*}{ Recurrence } & Positive & 29 & 25.22 & 0.0027 \\
\hline & Negative & 58 & 16.21 & \\
\hline
\end{tabular}

a, Mann-Whitney U-test, NOTE : Significant values are indicated in bold;

b, Body mass index; c, diabetes mellitus; d, well-differentiated hepatocellular carcinoma;

e, moderately or poorly differentiated hepatocellular carcinoma; f, Liver Cancer Study Group of Japan;

g, American Joint Committee on Cancer / International Union Against Cancer

for the plasma miR-224 analysis were 0.888 and 0.899 , respectively. These results clearly demonstrated that the plasma miR-224 level could satisfactory distinguish early stage HCC patients form healthy volunteers (Figure 4).

\section{Evaluation of whether plasma miR-224 expression reflects tumor dynamics}

To validate whether the plasma miR-224 level reflects tumor dynamics during the treatment of HCC patients, we first confirmed that the plasma miR-224 levels were significantly correlated with the tumor tissue levels of miR-224 using paired samples $(\mathrm{P}=0.0002)$ (Figure 3D). Second, we evaluated the plasma level of miR-224 in paired samples collected before and almost 1 month after surgery from $8 \mathrm{HCC}$ patients who underwent curative hepatectomy and observed that miR-224 was significantly reduced in these postoperative plasma samples $(\mathrm{P}=0.0058)$ (Figure $3 \mathrm{E})$. These results indicated that the plasma miR-224 level precisely reflects the HCC tissue status and could be used to trace tumor dynamics in HCC patients. 

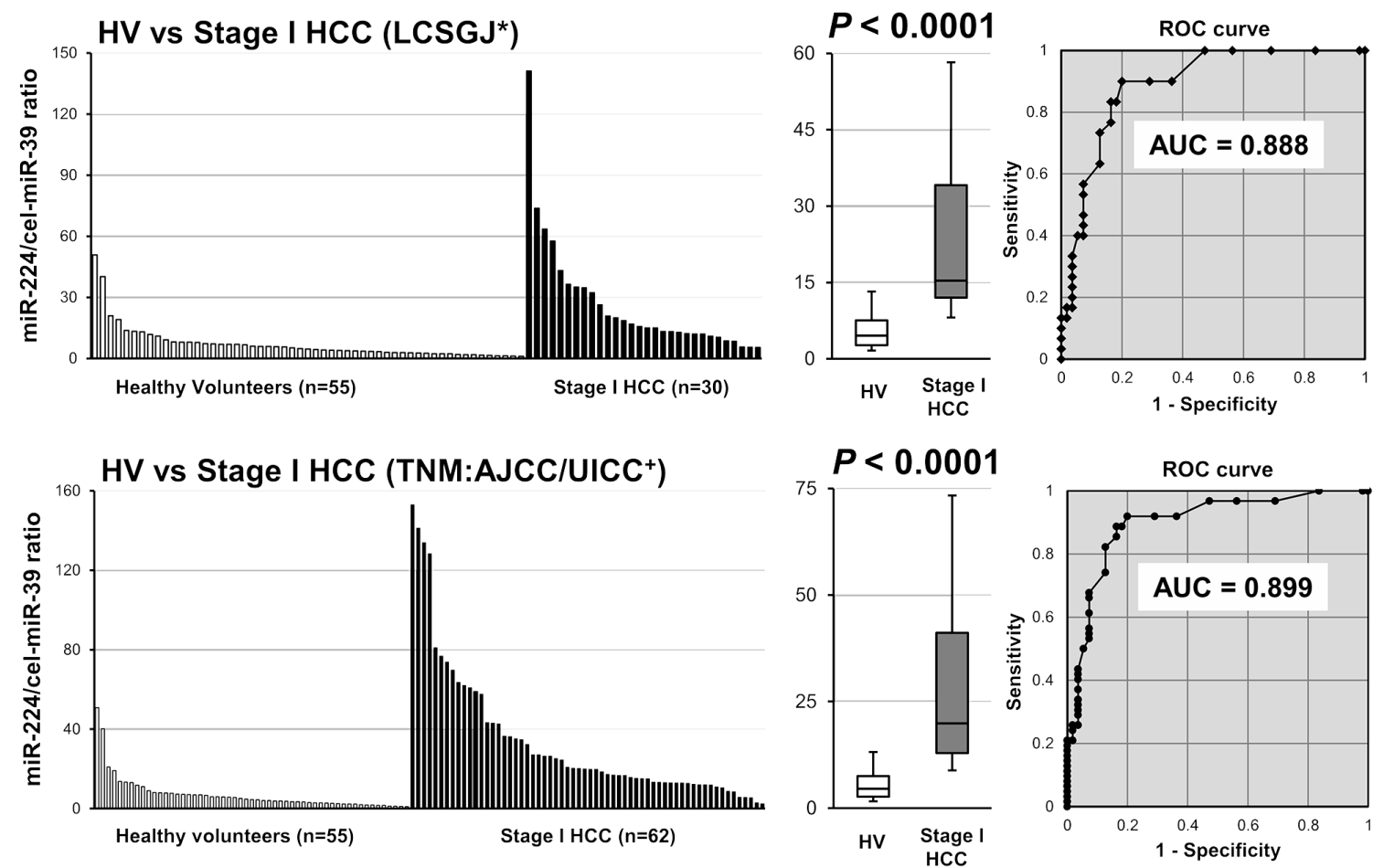

LCSGJ*: Liver Cancer Study Group of Japan, AJCC/UICC: AJCC+; American Joint Committee on Cancer, UICC; International Union Against Cancer

Figure 4: Evaluation of whether the plasma miR-224 level could satisfactory distinguish early stage HCC patients form healthy volunteers. The expression level of plasma miR-224 was significantly higher in stage I HCC patients than in healthy volunteers $(\mathrm{P}<0.0001)$. The AUC values in the LCSGJ and TNM (AJCC/UICC) staging systems for the plasma miR-224 analysis were 0.888 and 0.899 , respectively.

A Comparison of background liver diseases

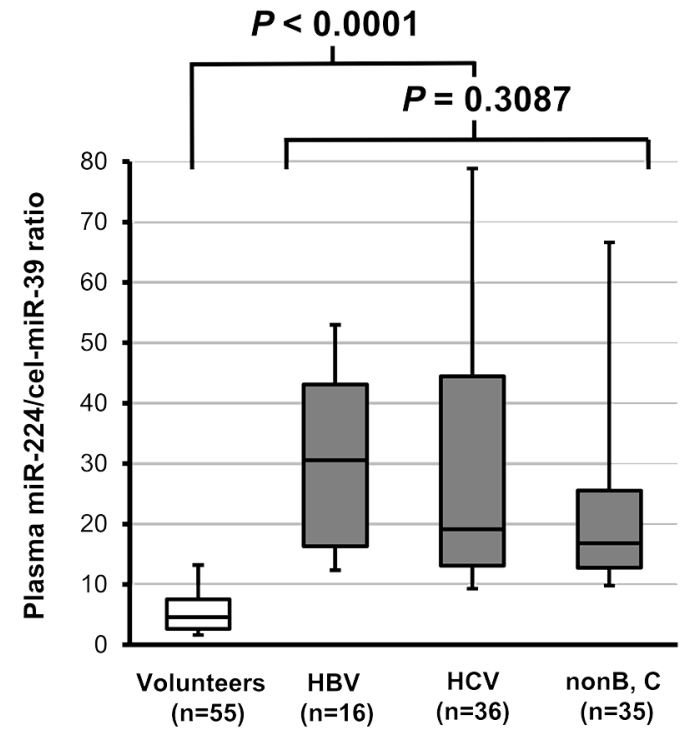

B Normal and slight liver dysfunction

$P=0.0008$

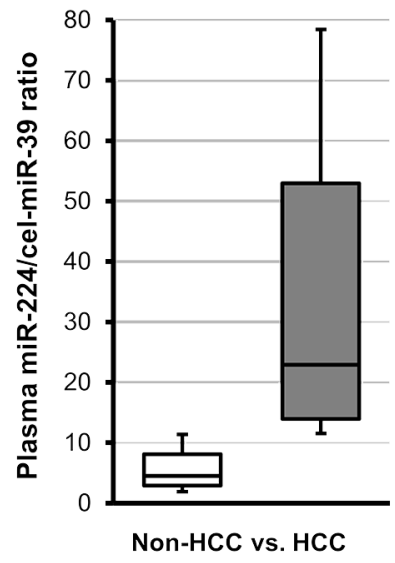

Figure 5: Evaluation of tumor detection based on the plasma miR-224 level, independent of chronic hepatic disease and hepatic function. A. There were no significant differences in the plasma miR-224 levels among patients with HBV, HCV and other disease in the large-scale analysis $(\mathrm{P}=0.3087)$. $\mathbf{B}, \mathbf{C}$. The plasma miR-224 levels were significantly higher in the plasma of HCC patients compared with non-HCC outpatients among patients with mild $(\mathrm{P}<0.0001)$ or severe liver dysfunction $(\mathrm{P}=0.0008)$. 


\section{Evaluation of tumor detection based on plasma miR-224 levels independent of chronic hepatic disease and hepatic function}

To demonstrate the clinical utility, we validated the plasma level of miR-224 in HCC patients without associated background liver disease and liver function. As shown in the test-scale analysis (Supplementary Figure $\mathrm{S} 1)$, there were no significant differences in the plasma miR-224 levels among patients with HBV, HCV and other disease in the large-scale analysis $(P=0.3087)$ (Figure $5 \mathrm{~A})$. The plasma miR-224 levels were significantly higher in HCC patients compared with non-HCC outpatients among individuals with mild (Figure 5B) or severe liver dysfunctions $(\mathrm{P}=0.0008$ ) (Figure $5 \mathrm{C})$. Furthermore, no significant correlation was observed between the plasma miR-224 levels and other clinical indicators, such as the tumor makers PIVKA-II (DCP) and AFP, the ICG retention rate (ICG 15R), total bilirubin (T-Bil), albumin(Alb), prothrombin time (PT (\%)), aspartate transaminase (AST) and alanine transaminase (ALT) (Figure 6).

\section{Correlation between the miR-224 plasma levels and the clinicopathological factors in $\mathrm{HCC}$ patients}

We analyzed whether plasma miR-224 levels were correlated with clinicopathological factors in the validation cohort comprising all 87 consecutive patients with HCC. The results showed that large tumor sizes of more than $20 \mathrm{~mm}$, an advanced pStage (LCSGJ) of more than II and the presence of recurrences were significantly correlated with high levels of plasma miR-224 ( $\mathrm{P}=$ $0.0005,0.0382$ and 0.0027 , respectively), whereas clinical factors, such as gender, age, BMI, diabetes, viral infection and liver cirrhosis, types of recurrence were not correlated with plasma miR-224 levels (Table 1, Supplementary Table S3A). These tendencies were same in two independent cohorts (Supplementary Table S2, S3B).

\section{Comparison of the minimum tumor detectability between plasma miR-224 and conventional serum tumor markers}

Next, we compared the minimum tumor detectability between plasma miR-224 and conventional serum tumor markers, such as PIVKA-II and AFP, in 54 consecutive HCC patients who underwent hepatectomy at Kyoto Prefectural University of Medicine (First Cohort) and 33 consecutive HCC patients who underwent hepatectomy at Kyoto Second Red Cross Hospital (Second Cohort). Regarding the cut-off value of plasma miR-224, the most sensitive cut-off value, determined using the ROC curve to detect the smallest tumor, was used (Supplementary Table S4). As shown in Table 2, the plasma miR-224 level was more sensitive to the presence of smaller tumors than were conventional tumor markers, such as PIVKA-II
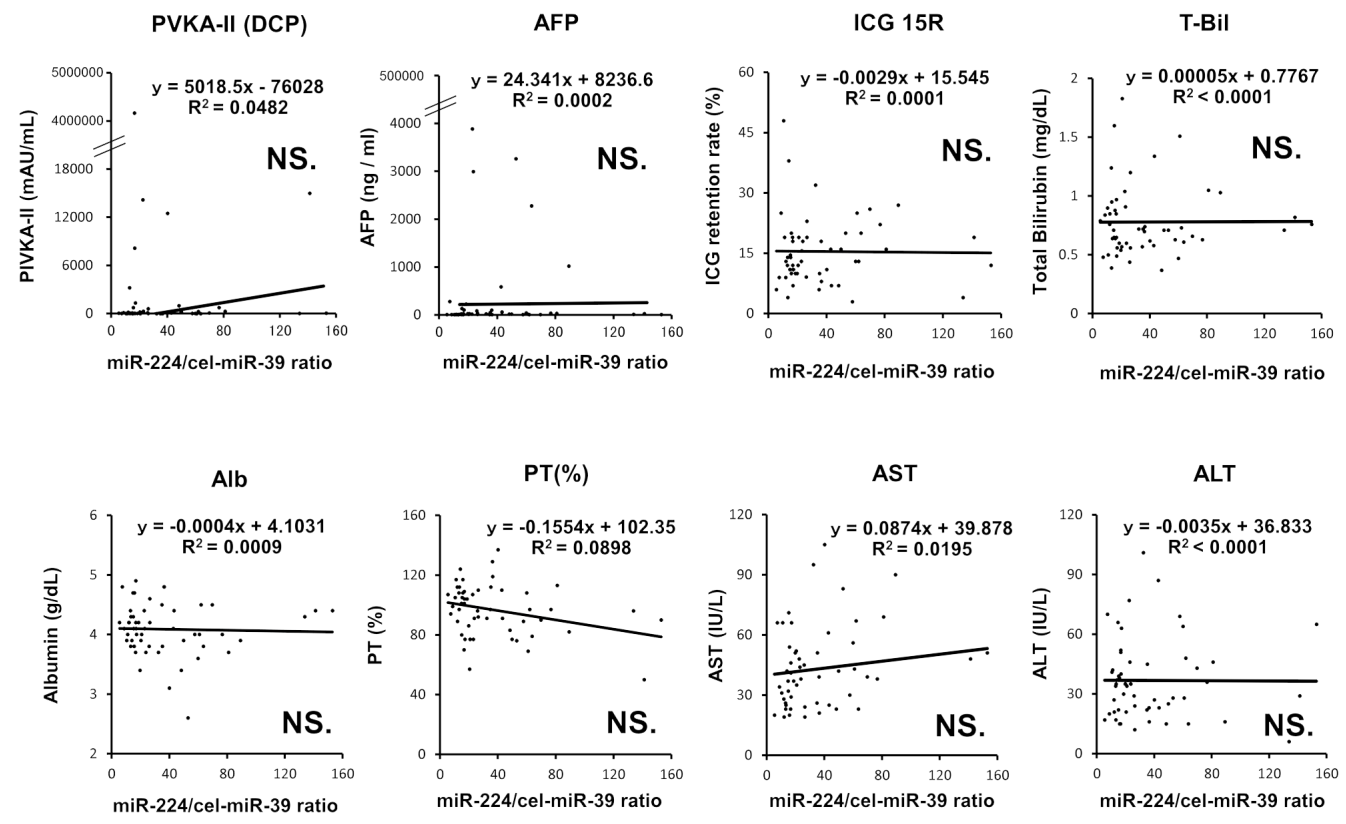

Figure 6: Correlation between the plasma level of miR-224 and conventional serum tumor markers and indicators of hepatic functions in HCC patients. No significant correlation was observed between the plasma miR-224 levels and other clinical indicators, such as the tumor makers PIVKA-II (DCP) and AFP, the ICG retention rate (ICG 15R), total bilirubin (T-Bil), albumin (Alb), prothrombin time (PT (\%)), aspartate transaminase (AST) and alanine transaminase (ALT). 
Table 2: Comparison of tumor detectability between plasma miR-224 level and conventional serum tumor markers

\begin{tabular}{|c|c|c|c|c|}
\hline \multicolumn{5}{|l|}{ First cohort } \\
\hline Biomarkers & $\mathbf{A U C}$ & $\begin{array}{c}\text { Minimum } \\
\text { detectable tumor } \\
\text { size }\end{array}$ & $\begin{array}{l}\text { Sensitivity (Tumor } \\
<18 \mathrm{~mm} \text { ) }\end{array}$ & $\begin{array}{l}\text { Sensitivity (all } \\
\text { patients) }\end{array}$ \\
\hline $\begin{array}{l}\text { Plasma miR-224 } \\
\text { cut-off value: } 11 *\end{array}$ & 0.802 & $18 \mathrm{~mm}$ & $80.0 \%$ & $90.7 \%$ \\
\hline $\begin{array}{l}\text { Serum PIVKA-II } \\
\text { cut-off value: } 40^{* *}\end{array}$ & 0.741 & $21 \mathrm{~mm}$ & $45.0 \%$ & $62.2 \%$ \\
\hline $\begin{array}{l}\text { Serum AFP } \\
\text { cut-off value: } 20^{* * *}\end{array}$ & 0.475 & $78 \mathrm{~mm}$ & $50.0 \%$ & $40.7 \%$ \\
\hline \multicolumn{5}{|c|}{$*$ miR-224/cel-miR-39 ratio, $* *$ mAU/ml, $* * *$ ng/ml } \\
\hline \multicolumn{5}{|c|}{ Second cohort } \\
\hline Biomarkers & AUC & $\begin{array}{c}\text { Minimum } \\
\text { detectable tumor } \\
\text { size }\end{array}$ & $\begin{array}{c}\text { Sensitivity (Tumor } \\
<18 \mathrm{~mm} \text { ) }\end{array}$ & $\begin{array}{l}\text { Sensitivity (all } \\
\text { patients) }\end{array}$ \\
\hline $\begin{array}{l}\text { Plasma miR-224 } \\
\text { cut-off value: } 11^{*}\end{array}$ & 0.731 & $18 \mathrm{~mm}$ & $63.6 \%$ & $78.7 \%$ \\
\hline $\begin{array}{l}\text { Serum PIVKA-II } \\
\text { cut-off value: } 40^{* *}\end{array}$ & 0.595 & $28 \mathrm{~mm}$ & $50.0 \%$ & $50.0 \%$ \\
\hline $\begin{array}{l}\text { Serum AFP } \\
\text { cut-off value: } 20 * * *\end{array}$ & 0.726 & $26 \mathrm{~mm}$ & $20.0 \%$ & $30.3 \%$ \\
\hline
\end{tabular}

*miR-224/cel-miR-39 ratio, ** mAU/ml, *** ng/ml

and AFP. Specifically, the plasma miR-224 level could detect a small tumor of less than $18 \mathrm{~mm}$ with highest AUC value. These results were clearly demonstrated in two independent cohorts.

\section{Post-treatment plasma miR-224 level as a sensitive indicator of residual tumor}

Because current tumor markers and imaging modalities, such as Lipiodol ${ }^{\circledR}-\mathrm{CT}$ and dynamic MRI, have limitations in the detection of the residual tumor after local therapy for HCC (Figure 7B), we investigated whether plasma miR-224 could sensitively detect residual tumors. We analyzed 10 patients with subsequently resected tumors after local therapies, such as percutaneous ablation therapy and TACE. Pathologically, 2 patients had no remaining cancer cells, whereas the remaining 8 patients had residual tumors. The plasma miR-224 levels were significantly higher in the 8 patients with residual tumors than in patients without remaining cancer cells $(\mathrm{P}=0.0318)$ (Figure 7A). In these patients, conventional tumor markers and dynamic MRI could not discriminate the residual HCC (Figure 7B).

\section{DISCUSSION}

No ideal and generally accepted blood-based molecular biomarkers, the so-called liquid biopsy, for the sensitive cancer screening and monitoring of HCC independent of background hepatic diseases and hepatic function have been identified. In the present study, we selected candidate miRNAs through a systematic review of $\mathrm{HCC}$ in the NCBI database and various validation analyses and identified plasma miR-224 as a novel biomarker for HCC diagnosis and treatment. Specifically, the expression level of plasma miR-224 was significantly higher in HCC patients than in healthy volunteers in two independent-cohorts and large-scale analyses (AUC: 0.908 ). Moreover, the detectability of HCC using plasma miR-224 was excellent and independent of background liver etiologies and the degree of liver dysfunction, even in liver cirrhosis. These findings might facilitate a more sensitive diagnosis and better decision-making during HCC treatment, strongly highlighting the usefulness of miR-224 as a novel and non-invasive liquid-based biomarker for HCC.

Regarding the molecular function of miR-224, the expression of miR-224 is primarily regulated through 
signaling pathways, such as the NF- $\mathrm{BB}$ inflammatory signaling pathway and TGF- $\beta$ signaling pathways $[56$, $61]$. This molecule is also reported as a master regulator of cell cycle progression and its overexpression results in G1/S checkpoint release followed by accelerated cell growth [62]. Recent studies have shown that miR224 is more highly expressed in not only HCC but also esophageal cancer, non-small cell lung cancer, colorectal cancer, cervical cancer and glioma, and this molecule has a proliferative effect on these cancer cells through direct interactions with various tumor-suppressor genes, such as CAMKK2, ADAM17, Homeobox D 10 and RKIP [63-68]. Moreover, the clinical relevance of miR-224 had been reported as an indicator of chemoresistance to cisplatin, methotrexate and R-CHOP, radiation sensitivity and a prognostic factor of sorafenib-treated patients [69-74]. These findings strongly suggest that miR-224 might have a pivotal role in carcinogenesis and the development of HCC tumors. Thus, we hypothesized that the upregulation of plasma miR-224 might be associated with the aggressive clinical features and poor outcomes of HCC. Indeed, a high plasma miR-224 level was significantly associated with larger tumor size $(\mathrm{P}=0.0005)$, higher pathological stage $(\mathrm{P}=0.0382)$ and recurrence rate $(\mathrm{P}$ $=0.0027)$. Previous report already demonstrated the association between tumor size and recurrence, therefore, our results suggested that a high plasma miR-224 level is associated with tumor development [75]. Thus, plasma miR-224 levels might be a useful molecular biomarker for primary and recurrent $\mathrm{HCC}$ detection.

The most striking finding of the present study was that plasma miR-224 levels could discriminate HCC from non-HCC patients under various hepatic diseases, such as viral hepatitis, alcoholic liver disease, fatty liver, NAFLD, $\mathrm{AIH}$, liver cirrhosis, NASH and primary PBC (Figure $5 \mathrm{~B}$ and $5 \mathrm{C}$ ). Indeed, there was no significant correlation between the plasma miR-224 levels and various indicators of hepatic function, such as platelet, albumin, T-Bil, Alb, PT (\%), AST, ALT and ICG 15R (Figure 6 and Supplementary Figure S3B). In clinical settings, conventional tumor markers lack sufficient sensitivity and specificity to facilitate $\mathrm{HCC}$ detection, and previous reported biomarkers for HCC often reflect background liver disease and hepatic function [76-80]. Whereas, the effectiveness of plasma miR-224 was demonstrated to facilitate the sensitive $\mathrm{HCC}$ detection of smaller tumors of less than $18 \mathrm{~mm}$ (AUC: 0.802). The sensitivity for HCC detection in plasma miR-224 was 78.7-90.7\% (Table 2). This result indicates that the sensitivity of plasma miR224 was not inferior to that of recent imaging modalities such as ultrasonography, computed tomography (CT), gadolinium ethoxybenzyl diethlenetriamine pentaacetic

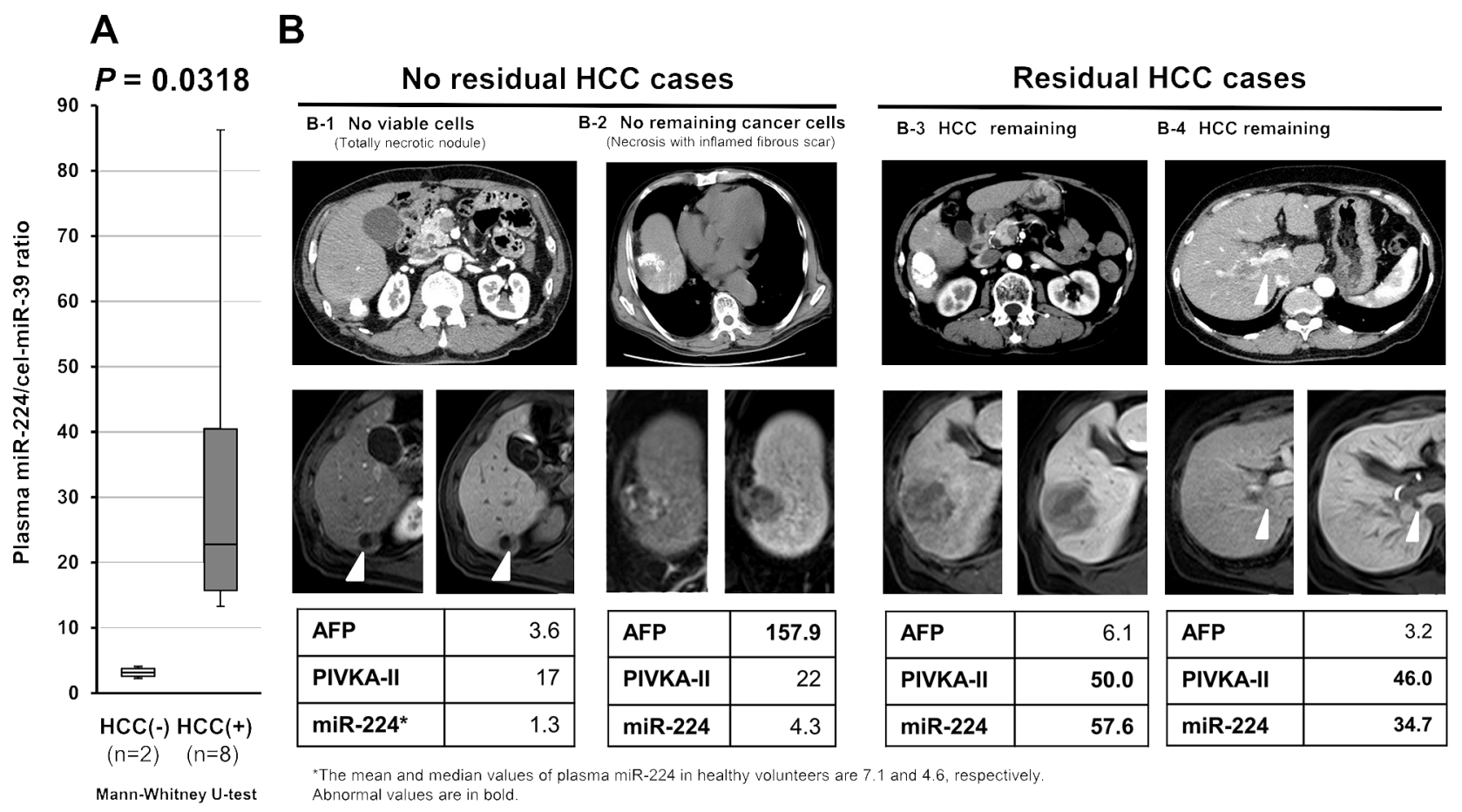

Figure 7: Post-treatment plasma miR-224 level as a sensitive indicator of residual tumor during HCC treatment. Current tumor markers and imaging modalities, such as Lipiodol ${ }^{\mathbb{B}}-\mathrm{CT}$ and dynamic MRI, have limitations in the detection of residual tumor after local therapy for HCC. (A) The plasma miR-224 level was significantly higher in patients with residual tumors than in patients with no remaining cancer cells $(\mathrm{P}=0.0318)(\mathbf{B})$ In these patients, conventional tumor markers and dynamic MRI could not discriminate residual HCC. 
acid-enhanced liver magnetic resonance imaging (GdEOB-DTPA-enhanced MRI), their sensitivities were $60.5 \%, 76.0 \%$ and $88.5 \%$, respectively [81-83]. Moreover, plasma miR-224 may be an indicator of residual tumor in non-surgical treatment such as percutaneous ablation therapy and/or TACE although this was preliminary result because the number of cases was small (Figure 7). These findings strongly suggest that plasma miR-224 can inform HCC treatment as a next-generation molecular bloodbased biomarker.

Regarding plasma miRNAs, previous studies concerning blood miRNA profiles revealed that the majority of circulating miRNAs were co-fractionated with plasma protein complexes [26]. Moreover, compared to serum, plasma might retain higher protein levels, including those of coagulant-related proteins. These finding prompt us to consistently use plasma miRNAs in future clinical application [25, 34-44]. Indeed, miRNA profiles and miRNA concentrations were considerably different between serum and plasma. Namely, this phenomenon was detected in studies of the diagnostic blood-based miRNA candidates in ESCC [41, 84] and pancreatic cancer [44, 85]. These findings strongly suggest that we should fully consider the kinds of blood samples such as serum, plasma and all blood for better clinical application of miRNAs as a blood-based biomarker. Although clinical utility of serum miR-224 in HCC was reported [86-88], our study might be also valuable as a first report to demonstrate the diagnostic utility of plasma miR-224 in HCC, independent of hepatic status.

This study is the first to demonstrate the diagnostic utility of plasma miR-224 in HCC, independent of hepatic status. However, many issues must be addressed before these findings can be translated into a clinically useful and non-invasive screening strategy for HCC patients. Namely, more sensitive candidate miRNAs should be identified as liquid-based biomarkers for the diagnosis and monitoring of $\mathrm{HCC}$ using strategies with different body fluids and high-throughput platforms, such as nextgeneration sequencing or digital PCR-based approaches. Furthermore, we will prospectively confirm the usefulness of plasma miR-224 in a larger number of patients with cancers, if possible, including not only HCC but also other types of cancer with miR-224 overexpression such as esophageal cancer, non-small cell lung cancer, colorectal cancer, cervical cancer and glioma. These strategies are currently under evaluation.

\section{MATERIALS AND METHODS}

\section{Patients and samples}

This study was approved by the Institutional Review Board of both Kyoto Prefectural University of Medicine and Kyoto Second Red Cross Hospital, Kyoto, Japan, and each subject provided signed informed consent. Between
January 2010 and December 2014, a total of 211 plasma samples were collected, including 109 samples from HCC patients, 75 samples from healthy volunteers and 27 samples from outpatients with chronic liver disease. The 109 plasma samples from HCC patients were obtained from Kyoto Prefectural University of Medicine and comprised 20 small-scale samples, 54 validation samples and 2 samples from patients who underwent resection following pretreatment, such as percutaneous ablation therapy and/or trans-catheter arterial chemoembolization therapy (TACE), and in whom no remaining cancer cells were found (1st cohort), and the 33 validation samples were obtained from Kyoto Second Red Cross Hospital (2nd cohort). The 27 plasma samples from outpatients with chronic liver disease were obtained from Kyoto Prefectural University of Medicine. These samples were divided into two groups: 16 outpatients diagnosed with viral hepatitis, alcoholic liver disease, fatty liver, non-alcoholic fatty liver disease (NAFLD) and autoimmune hepatitis (AIH), defined as "mild liver dysfunction outpatients," and 11 outpatients diagnosed with liver cirrhosis or NASH (non-alcoholic steatohepatitis) or primary biliary cirrhosis (PBC) were defined as "severe liver dysfunction outpatients." The 75 samples from healthy volunteers comprised 20 small-scale samples and 33 validation samples from Kyoto Prefectural University of Medicine (1st cohort) and 22 validation samples from Kyoto Second Red Cross Hospital (2nd cohort). These healthy volunteers included medical personnel and patients with benign diseases, such as cholelithiasis and inguinal hernia. The patients with benign diseases and outpatients with mild or severe liver dysfunction underwent medical examinations, including computed tomography and endoscopy, and were confirmed as not having HCC or any cancerous diseases.

Concerning the tissue samples from the patients who underwent hepatic resection, a total of $24 \mathrm{HCC}$ specimens and 17 normal hepatic specimens were collected. Half (12) of the HCC specimens were paired with validation plasma samples to determine a correlation, whereas the remaining (12) HCC specimens were paired with adjacent normal hepatic specimens resected from the same patients. A total of 5 adjacent normal hepatic specimens were obtained from patients who underwent hepatic resection for $\mathrm{HCC}$ and compared with HCC cell lines.

Peripheral blood $(7 \mathrm{ml})$ was obtained from each patient at the time of diagnosis or before surgery and from the healthy volunteers. The blood was transferred into sodium heparin tubes (BD Vacutainer, Franklin Lakes, New Jersey, the United States) and immediately subjected to a three-spin protocol (1500 r.p.m. for 30 min, 3000 r.p.m. for $5 \mathrm{~min}$, and 4500 r.p.m. for $5 \mathrm{~min}$ ) to prevent contamination with cellular nucleic acids. The plasma was collected and stored at $-80^{\circ} \mathrm{C}$ until further processing. The resected specimens were fixed in formalin and embedded in paraffin for pathological diagnosis. Histological evaluation was performed for tissues adjacent 
to specimens according to the criteria of the World Health Organization. In all cases, at least two pathologists agreed with pathological observations and confirmed the diagnosis. The tumor stages were assessed according to General Rules for the Clinical and Pathological Study of Primary Liver Cancer by Liver Cancer Study Group of Japan (LCSGJ) [89] and TNM classification system by American Joint Committee on Cancer (AJCC) and International Union Against Cancer (UICC) [90].

\section{RNA extraction}

Total RNA was extracted from $400 \mu \mathrm{l}$ of plasma using a mirVana PARIS Kit (Ambion, Austin, TX) and eluted into $100 \mu \mathrm{l}$ of preheated $\left(95^{\circ} \mathrm{C}\right)$ Elution Solution according to the manufacturer's protocol. A volume of $400 \mu \mathrm{l}$ of plasma was used as the common denominator in each microarray analysis; thus, there was no definite internal control in the plasma miRNA analyses as shown in previous studies [34-41]. Total RNA was also extracted from four $15-\mu \mathrm{m}$-thick slices of the formalin-fixed and paraffin-embedded tissue samples (60 $\mu \mathrm{m}$ thickness) using a Recover All Total Nucleic Acid Isolation Kit (Ambion) and subsequently eluted into $60 \mu \mathrm{l}$ of Elution Solution according to the manufacturer's instructions.

\section{A systematic review of the NCBI database to select candidate miRNAs}

We performed a systematic review of the NCBI database to identify novel plasma biomarkers of miRNA in patients with HCC (Figure 1B and Supplementary Table $\mathrm{S} 1$ ). We searched for all studies related to HCC miRNAs in PubMed up to February 2013. This search was based on the key terms 'HCC' and 'microRNA.' Any meeting abstracts not accompanied by full articles and other incomplete and non-English articles were excluded. The candidate miRNAs had to meet the following criteria: I) Candidate miRNAs whose overexpression was validated in HCC tissues compared with normal liver or peritumoral non-cancerous tissues; II) Candidate miRNAs not previously reported as biomarkers in body fluids, such as plasma, serum, urine and semen; III) Candidate miRNAs demonstrated to have oncogenic roles (functionally unknown or tumor suppressive miRNAs were excluded); and IV) Candidate miRNAs reported several times with sufficient data in HCC. Two authors independently reviewed all articles identified in this search using these criteria, and a third author resolved any discrepancies.

\section{Quantification of miRNA by qRT-PCR}

The amounts of miRNAs were quantified by qRT-PCR using a human TaqMan MicroRNA Assay Kit (Applied Biosystems, Foster City, CA). A reverse transcription reaction was performed using a TaqMan
MicroRNA Reverse Transcription Kit (Applied Biosystems) in $5 \mu \mathrm{l}$ of solution containing $1.67 \mu \mathrm{l}$ of extracted RNA, $0.05 \mu \mathrm{l}$ of $100 \mathrm{mM}$ dNTPs, $0.33 \mu \mathrm{l}$ of Multiscribe Reverse Transcriptase $\left(50 \mathrm{U} \mu \mathrm{l}^{-1}\right), 0.5 \mu \mathrm{l}$ of $10 \times$ Reverse Transcription Buffer, $0.06 \mu \mathrm{l}$ of RNase

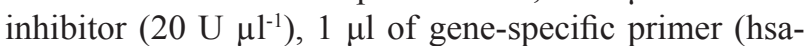
miR-151, Assay ID: 000596; hsa-miR-155, Assay ID: 000479; hsa-miR-191, Assay ID: 000490; hsa-miR-224, Assay ID: 000599; cel-miR-39, Assay ID: 000200; and RNU6B, Assay ID: 001093), and $1.39 \mu \mathrm{l}$ of nucleasefree water. To synthesize cDNA, the reaction mixtures were incubated at $16^{\circ} \mathrm{C}$ for $30 \mathrm{~min}, 42^{\circ} \mathrm{C}$ for $30 \mathrm{~min}$, and $85^{\circ} \mathrm{C}$ for $5 \mathrm{~min}$, after which the reactions were held at $4^{\circ} \mathrm{C}$. Next, $0.67 \mu \mathrm{l}$ of cDNA was amplified using 5 $\mu l$ of TaqMan $2 \times$ Universal PCR Master Mix with no AmpErase UNG (Applied Biosystems), $0.5 \mu 1$ of genespecific primers/probe, and $3.83 \mu 1$ of nuclease-free water in a final volume of $10 \mu \mathrm{l}$. Quantitative PCR was run on a StepOnePlus PCR system (Applied Biosystems), and the reaction mixtures were incubated at $95^{\circ} \mathrm{C}$ for $10 \mathrm{~min}$, followed by 40 cycles of $95^{\circ} \mathrm{C}$ for $15 \mathrm{sec}$ and $60^{\circ} \mathrm{C}$ for 1 min. The cycle threshold $(\mathrm{Ct})$ values were calculated using StepOne Software v2.0 (Applied Biosystems).

As previously reported [22], we used an approach to data normalization based on spiking the sample with a synthetic RNA oligonucleotide, cel-miR-39, which does not exist in the human genome. C. elegans cel-miR-39 was purchased as a custom-made RNA oligonucleotide (Qiagen, Valencia, CA). The oligo used for spiking, as a mixture of $25 \mathrm{fmol}$ of the oligonucleotide in a total volume of $5 \mu \mathrm{l}$ of water, was introduced after the addition of $2 \mathrm{X}$ Denaturing Solution (Ambion) to the plasma or serum sample to avoid degradation by endogenous plasma RNases. As a control for each RNA sample, cel-miR-39 was used for TaqMan qRT-PCR assays (Applied Biosystems) as previously described. The data were normalized across samples using the $2^{-\Delta \Delta \mathrm{Ct}}$ method relative to cel-miR-39. The miRNA expression from tissue samples and cultured cells was normalized using the $2^{-\Delta \Delta \mathrm{Ct}}$ method relative to U6 small nuclear RNA (RNU6B). The $\Delta \mathrm{Ct}$ was calculated after subtracting the $\mathrm{Ct}$ values of celmiR-39 or RNU6B from those of the miRNAs of interest. The $\Delta \Delta \mathrm{Ct}$ was subsequently calculated after subtracting the mean of $\Delta \mathrm{Ct}$ of the plasma of healthy volunteers or normal pancreatic tissue samples from the $\triangle \mathrm{Ct}$ of $\mathrm{HCC}$ tissues. Changes in gene expression were calculated using the equation $2^{-\Delta \Delta \mathrm{Ct}}[91-92]$.

\section{Culture of $\mathrm{HCC}$ cell lines}

The HCC cell lines JHH-6, HLE and Alexander were purchased from the JCRB Cell Bank (Osaka, Japan), and HepG2 was purchased from the RIKEN cell bank (Tsukuba, JAPAN) and cultured in Roswell Park Memorial Institute (RPMI)-1640 medium (Sigma, St Louis, MO), Dulbecco's Modified Eagle Medium (DMEM, Nacalai Tesque, 
JAPAN) and William's Medium E (LANZA, Switzerland) supplemented with 10\% FBS (Trace Scientific, Melbourne, Australia). All cell lines were cultured in 5\% carbon dioxide at $37^{\circ} \mathrm{C}$ in a humidified chamber.

\section{Statistical analysis}

The Mann-Whitney U-test for unpaired data from plasma or tissue samples was performed. The KruskalWallis H-test was also used to compare more than two groups. The Wilcoxon test was used to compare the paired HCC and adjacent normal hepatic tissue samples and the paired plasma samples obtained before and at 1 month after hepatectomy. The Chi-square test or Fisher's exact probability test was used to evaluate correlations between the results for the plasma miRNA levels and clinicopathological factors. A P-value $<0.05$ was considered statistically significant.

Receiver-operating characteristic curves and the area under the ROC curve were used to assess the feasibility of using plasma miRNA as a diagnostic tool for detecting HCC. The Youden index was used to determine the cut-off value for the plasma miRNA levels [59].

\section{ACKNOWLEDGMENTS}

The authors thank Yoshio Sumida, MD, Ph.D. and Michihisa Moriguchi, MD, Ph.D. (Department of Molecular Gastroenterology and Hepatology, Kyoto Prefectural University of Medicine, Kyoto, Japan), and Momoko Todo, MD, Ph.D. and Yutaka Kondo, MD, Ph.D. (Department of Surgery, Kyoto Second Red Cross Hospital, Kyoto, Japan) for supporting this research.

\section{CONFLICTS OF INTEREST}

We have no financial relationships to disclose.

\section{REFERENCES}

1. Ferlay J, Soerjomataram I, Dikshit R, Eser S, Mathers C, Rebelo M, Parkin DM, Forman D and Bray F. Cancer incidence and mortality worldwide: sources, methods and major patterns in GLOBOCAN 2012. International journal of cancer. 2015; 136:E359-386.

2. Tateishi R, Okanoue T, Fujiwara N, Okita K, Kiyosawa K, Omata M, Kumada H, Hayashi N and Koike K. Clinical characteristics, treatment, and prognosis of non-B, non- $\mathrm{C}$ hepatocellular carcinoma: a large retrospective multicenter cohort study. Journal of gastroenterology. 2015; 50:350-360.

3. Parkin DM. The global health burden of infectionassociated cancers in the year 2002. International journal of cancer. 2006; 118:3030-3044.

4. Mayans MV, Calvet X, Bruix J, Bruguera M, Costa J, Esteve J, Bosch FX, Bru C and Rodes J. Risk factors for hepatocellular carcinoma in Catalonia, Spain. International journal of cancer. 1990; 46:378-381.

5. Donato F, Tagger A, Gelatti U, Parrinello G, Boffetta P, Albertini A, Decarli A, Trevisi P, Ribero ML, Martelli C, Porru S and Nardi G. Alcohol and hepatocellular carcinoma: the effect of lifetime intake and hepatitis virus infections in men and women. American journal of epidemiology. 2002; 155:323-331.

6. Calle EE, Rodriguez C, Walker-Thurmond $\mathrm{K}$ and Thun MJ. Overweight, obesity, and mortality from cancer in a prospectively studied cohort of U.S. adults. The New England journal of medicine. 2003; 348:1625-1638.

7. El-Serag HB, Tran T and Everhart JE. Diabetes increases the risk of chronic liver disease and hepatocellular carcinoma. Gastroenterology. 2004; 126:460-468.

8. Newell P, Toffanin S, Villanueva A, Chiang DY, Minguez B, Cabellos L, Savic R, Hoshida Y, Lim KH, Melgar-Lesmes P, Yea S, Peix J, Deniz K, Fiel MI, Thung S, Alsinet C, et al. Ras pathway activation in hepatocellular carcinoma and anti-tumoral effect of combined sorafenib and rapamycin in vivo. Journal of hepatology. 2009; 51:725-733.

9. Grabinski N, Ewald F, Hofmann BT, Staufer K, Schumacher U, Nashan B and Jucker M. Combined targeting of AKT and mTOR synergistically inhibits proliferation of hepatocellular carcinoma cells. Molecular cancer. 2012; 11:85.

10. Thompson MD and Monga SP. WNT/beta-catenin signaling in liver health and disease. Hepatology (Baltimore, Md). 2007; 45:1298-1305.

11. Sicklick JK, Li YX, Jayaraman A, Kannangai R, Qi Y, Vivekanandan P, Ludlow JW, Owzar K, Chen W, Torbenson MS and Diehl AM. Dysregulation of the Hedgehog pathway in human hepatocarcinogenesis. Carcinogenesis. 2006; 27:748-757.

12. Ueki T, Fujimoto J, Suzuki T, Yamamoto H and Okamoto E. Expression of hepatocyte growth factor and its receptor c-met proto-oncogene in hepatocellular carcinoma. Hepatology (Baltimore, Md). 1997; 25:862-866.

13. Schiffer E, Housset C, Cacheux W, Wendum D, DesboisMouthon C, Rey C, Clergue F, Poupon R, Barbu V and Rosmorduc O. Gefitinib, an EGFR inhibitor, prevents hepatocellular carcinoma development in the rat liver with cirrhosis. Hepatology (Baltimore, Md). 2005; 41:307-314.

14. Tateishi R, Yoshida H, Matsuyama Y, Mine N, Kondo Y and Omata M. Diagnostic accuracy of tumor markers for hepatocellular carcinoma: a systematic review. Hepatology international. 2008; 2:17-30.

15. Sterling RK, Jeffers L, Gordon F, Venook AP, Reddy KR, Satomura S, Kanke F, Schwartz ME and Sherman M. Utility of Lens culinaris agglutinin-reactive fraction of alphafetoprotein and des-gamma-carboxy prothrombin, alone or in combination, as biomarkers for hepatocellular carcinoma. Clinical gastroenterology and hepatology. 2009; 7:104-113. 
16. Yoon $\mathrm{YJ}$, Han $\mathrm{KH}$ and Kim do Y. Role of serum prothrombin induced by vitamin $\mathrm{K}$ absence or antagonist-II in the early detection of hepatocellular carcinoma in patients with chronic hepatitis B virus infection. Scandinavian journal of gastroenterology. 2009; 44:861-866.

17. Lee RC, Feinbaum RL and Ambros V. The C. elegans heterochronic gene lin-4 encodes small RNAs with antisense complementarity to lin-14. Cell. 1993; 75:843-854.

18. He L, Thomson JM, Hemann MT, Hernando-Monge E, Mu D, Goodson S, Powers S, Cordon-Cardo C, Lowe SW, Hannon GJ and Hammond SM. A microRNA polycistron as a potential human oncogene. Nature. 2005; 435:828-833.

19. Calin GA and Croce CM. MicroRNA signatures in human cancers. Nature reviews Cancer. 2006; 6:857-866.

20. He L, He X, Lim LP, de Stanchina E, Xuan Z, Liang Y, Xue W, Zender L, Magnus J, Ridzon D, Jackson AL, Linsley PS, Chen C, Lowe SW, Cleary MA and Hannon GJ. A microRNA component of the p53 tumour suppressor network. Nature. 2007; 447:1130-1134.

21. Lu J, Getz G, Miska EA, Alvarez-Saavedra E, Lamb J, Peck D, Sweet-Cordero A, Ebert BL, Mak RH, Ferrando AA, Downing JR, Jacks T, Horvitz HR and Golub TR. MicroRNA expression profiles classify human cancers. Nature. 2005; 435:834-838.

22. Mitchell PS, Parkin RK, Kroh EM, Fritz BR, Wyman SK, Pogosova-Agadjanyan EL, Peterson A, Noteboom J, O'Briant KC, Allen A, Lin DW, Urban N, Drescher CW, Knudsen BS, Stirewalt DL, Gentleman R, et al. Circulating microRNAs as stable blood-based markers for cancer detection. Proceedings of the National Academy of Sciences of the United States of America. 2008; 105:10513-10518.

23. Chen X, Ba Y, Ma L, Cai X, Yin Y, Wang K, Guo J, Zhang Y, Chen J, Guo X, Li Q, Li X, Wang W, Zhang Y, Wang J, Jiang X, et al. Characterization of microRNAs in serum: a novel class of biomarkers for diagnosis of cancer and other diseases. Cell research. 2008; 18:997-1006.

24. Filipowicz W, Bhattacharyya SN and Sonenberg N. Mechanisms of post-transcriptional regulation by microRNAs: are the answers in sight? Nature reviews Genetics. 2008; 9:102-114.

25. Ichikawa D, Komatsu S, Konishi $\mathrm{H}$ and Otsuji E. Circulating microRNA in digestive tract cancers. Gastroenterology. 2012; 142:1074-1078.e1071.

26. Arroyo JD, Chevillet JR, Kroh EM, Ruf IK, Pritchard CC, Gibson DF, Mitchell PS, Bennett CF, Pogosova-Agadjanyan EL, Stirewalt DL, Tait JF and Tewari M. Argonaute2 complexes carry a population of circulating microRNAs independent of vesicles in human plasma. Proceedings of the National Academy of Sciences of the United States of America. 2011; 108:5003-5008.

27. Vickers KC, Palmisano BT, Shoucri BM, Shamburek RD and Remaley AT. MicroRNAs are transported in plasma and delivered to recipient cells by high-density lipoproteins. Nature cell biology. 2011; 13:423-433.
28. Kosaka N, Iguchi H and Ochiya T. Circulating microRNA in body fluid: a new potential biomarker for cancer diagnosis and prognosis. Cancer science. 2010; 101:2087-2092.

29. Hasselmann DO, Rappl G, Tilgen W and Reinhold U. Extracellular tyrosinase mRNA within apoptotic bodies is protected from degradation in human serum. Clinical chemistry. 2001; 47:1488-1489.

30. Cocucci E, Racchetti G and Meldolesi J. Shedding microvesicles: artefacts no more. Trends in cell biology. 2009; 19:43-51.

31. Valadi H, Ekstrom K, Bossios A, Sjostrand M, Lee JJ and Lotvall JO. Exosome-mediated transfer of mRNAs and microRNAs is a novel mechanism of genetic exchange between cells. Nature cell biology. 2007; 9:654-659.

32. Skog J, Wurdinger T, van Rijn S, Meijer DH, Gainche L, Sena-Esteves M, Curry WT, Jr., Carter BS, Krichevsky AM and Breakefield XO. Glioblastoma microvesicles transport RNA and proteins that promote tumour growth and provide diagnostic biomarkers. Nature cell biology. 2008; 10:1470-1476.

33. Rechavi O, Erlich Y, Amram H, Flomenblit L, Karginov FV, Goldstein I, Hannon GJ and Kloog Y. Cell contactdependent acquisition of cellular and viral nonautonomously encoded small RNAs. Genes \& development. 2009; 23:1971-1979.

34. Tsujiura M, Ichikawa D, Komatsu S, Shiozaki A, Takeshita H, Kosuga T, Konishi H, Morimura R, Deguchi K, Fujiwara $\mathrm{H}$, Okamoto $\mathrm{K}$ and Otsuji E. Circulating microRNAs in plasma of patients with gastric cancers. British journal of cancer. 2010; 102:1174-1179.

35. Komatsu S, Ichikawa D, Takeshita H, Tsujiura M, Morimura R, Nagata H, Kosuga T, Iitaka D, Konishi H, Shiozaki A, Fujiwara H, Okamoto $\mathrm{K}$ and Otsuji E. Circulating microRNAs in plasma of patients with oesophageal squamous cell carcinoma. British journal of cancer. 2011; 105:104-111.

36. Morimura R, Komatsu S, Ichikawa D, Takeshita H, Tsujiura M, Nagata H, Konishi H, Shiozaki A, Ikoma H, Okamoto K, Ochiai T, Taniguchi $\mathrm{H}$ and Otsuji E. Novel diagnostic value of circulating miR-18a in plasma of patients with pancreatic cancer. British journal of cancer. 2011; 105:1733-1740.

37. Komatsu S, Ichikawa D, Takeshita H, Konishi H, Nagata H, Hirajima S, Kawaguchi T, Arita T, Shiozaki A, Fujiwara H, Okamoto K and Otsuji E. Prognostic impact of circulating miR-21 and miR-375 in plasma of patients with esophageal squamous cell carcinoma. Expert opinion on biological therapy. 2012; 12:S53-59.

38. Konishi H, Ichikawa D, Komatsu S, Shiozaki A, Tsujiura M, Takeshita H, Morimura R, Nagata H, Arita T, Kawaguchi T, Hirashima S, Fujiwara H, Okamoto K and Otsuji E. Detection of gastric cancer-associated microRNAs on microRNA microarray comparing pre- and post-operative plasma. British journal of cancer. 2012; 106:740-747.

39. Hirajima S, Komatsu S, Ichikawa D, Takeshita H, Konishi $\mathrm{H}$, Shiozaki A, Morimura R, Tsujiura M, Nagata H, 
Kawaguchi T, Arita T, Kubota T, Fujiwara H, Okamoto $\mathrm{K}$ and Otsuji E. Clinical impact of circulating miR-18a in plasma of patients with oesophageal squamous cell carcinoma. British journal of cancer. 2013; 108:1822-1829.

40. Kawaguchi T, Komatsu S, Ichikawa D, Morimura R, Tsujiura M, Konishi H, Takeshita H, Nagata H, Arita T, Hirajima S, Shiozaki A, Ikoma H, Okamoto K, Ochiai T, Taniguchi $\mathrm{H}$ and Otsuji E. Clinical impact of circulating miR-221 in plasma of patients with pancreatic cancer. British journal of cancer. 2013; 108:361-369.

41. Komatsu S, Ichikawa D, Hirajima S, Kawaguchi T, Miyamae M, Okajima W, Ohashi T, Arita T, Konishi H, Shiozaki A, Fujiwara H, Okamoto K, Yagi N and Otsuji E. Plasma microRNA profiles: identification of miR-25 as a novel diagnostic and monitoring biomarker in oesophageal squamous cell carcinoma. British journal of cancer. 2014; 111:1614-1624.

42. Tsujiura M, Komatsu S, Ichikawa D, Shiozaki A, Konishi H, Takeshita H, Moriumura R, Nagata H, Kawaguchi T, Hirajima S, Arita T, Fujiwara H, Okamoto K and Otsuji E. Circulating miR-18a in plasma contributes to cancer detection and monitoring in patients with gastric cancer. Gastric cancer. 2015; 18:271-279.

43. Komatsu S, Ichikawa D, Miyamae M, Kawaguchi T, Morimura R, Hirajima S, Okajima W, Ohashi T, Imamura T, Konishi H, Shiozaki A, Ikoma H, Okamoto K, Taniguchi $\mathrm{H}$ and Otsuji E. Malignant potential in pancreatic neoplasm; new insights provided by circulating miR-223 in plasma. Expert opinion on biological therapy. 2015; 15:773-785.

44. Miyamae M, Komatsu S, Ichikawa D, Kawaguchi T, Hirajima S, Okajima W, Ohashi T, Imamura T, Konishi H, Shiozaki A, Morimura R, Ikoma H, Ochiai T, Okamoto $\mathrm{K}$, Taniguchi $\mathrm{H}$ and Otsuji E. Plasma microRNA profiles: identification of miR-744 as a novel diagnostic and prognostic biomarker in pancreatic cancer. British journal of cancer. 2015; 113:1467-1476.

45. Xu J, Wu C, Che X, Wang L, Yu D, Zhang T, Huang L, Li H, Tan W, Wang C and Lin D. Circulating microRNAs, miR21, miR-122, and miR-223, in patients with hepatocellular carcinoma or chronic hepatitis. Molecular carcinogenesis. 2011; 50:136-142.

46. Qu KZ, Zhang K, Li H, Afdhal NH and Albitar M. Circulating microRNAs as biomarkers for hepatocellular carcinoma. Journal of clinical gastroenterology. 2011; 45:355-360.

47. Zhang YC, Xu Z, Zhang TF and Wang YL. Circulating microRNAs as diagnostic and prognostic tools for hepatocellular carcinoma. World journal of gastroenterology. 2015; 21:9853-9862.

48. Luedde T. MicroRNA-151 and its hosting gene FAK (focal adhesion kinase) regulate tumor cell migration and spreading of hepatocellular carcinoma. Hepatology (Baltimore, Md). 2010; 52:1164-1166.

49. Ding J, Huang S, Wu S, Zhao Y, Liang L, Yan M, Ge C, Yao J, Chen T, Wan D, Wang H, Gu J, Yao M, Li J, Tu
$\mathrm{H}$ and $\mathrm{He} \mathrm{X}$. Gain of miR-151 on chromosome 8q24.3 facilitates tumour cell migration and spreading through downregulating RhoGDIA. Nature cell biology. 2010; 12:390-399.

50. Han ZB, Chen HY, Fan JW, Wu JY, Tang HM and Peng ZH. Up-regulation of microRNA-155 promotes cancer cell invasion and predicts poor survival of hepatocellular carcinoma following liver transplantation. Journal of cancer research and clinical oncology. 2012; 138:153-161.

51. Xie Q, Chen X, Lu F, Zhang T, Hao M, Wang Y, Zhao $\mathrm{J}$, McCrae MA and Zhuang H. Aberrant expression of microRNA 155 may accelerate cell proliferation by targeting sex-determining region Y box 6 in hepatocellular carcinoma. Cancer. 2012; 118:2431-2442.

52. Elyakim E, Sitbon E, Faerman A, Tabak S, Montia E, Belanis L, Dov A, Marcusson EG, Bennett CF, Chajut A, Cohen D and Yerushalmi N. hsa-miR-191 is a candidate oncogene target for hepatocellular carcinoma therapy. Cancer research. 2010; 70:8077-8087.

53. He Y, Cui Y, Wang W, Gu J, Guo S, Ma K and Luo X. Hypomethylation of the hsa-miR-191 locus causes high expression of hsa-mir-191 and promotes the epithelialto-mesenchymal transition in hepatocellular carcinoma. Neoplasia (New York, NY). 2011; 13:841-853.

54. Zhang Y, Takahashi S, Tasaka A, Yoshima T, Ochi H and Chayama K. Involvement of microRNA-224 in cell proliferation, migration, invasion, and anti-apoptosis in hepatocellular carcinoma. Journal of gastroenterology and hepatology. 2013; 28:565-575.

55. Wang Y, Toh HC, Chow P, Chung AY, Meyers DJ, Cole PA, Ooi LL and Lee CG. MicroRNA-224 is up-regulated in hepatocellular carcinoma through epigenetic mechanisms. FASEB journal. 2012; 26:3032-3041.

56. Scisciani C, Vossio S, Guerrieri F, Schinzari V, De Iaco R, D’Onorio de Meo P, Cervello M, Montalto G, Pollicino T, Raimondo G, Levrero M and Pediconi N. Transcriptional regulation of miR-224 upregulated in human HCCs by NFkappaB inflammatory pathways. Journal of hepatology. 2012; 56:855-861.

57. Wang Y and Lee CG. Role of miR-224 in hepatocellular carcinoma: a tool for possible therapeutic intervention? Epigenomics. 2011; 3:235-243.

58. Diaz G, Melis M, Tice A, Kleiner DE, Mishra L, Zamboni $\mathrm{F}$ and Farci P. Identification of microRNAs specifically expressed in hepatitis C virus-associated hepatocellular carcinoma. International journal of cancer. 2013; 133:816-824.

59. Akobeng AK. Understanding diagnostic tests 3: Receiver operating characteristic curves. Acta paediatrica (Oslo, Norway : 1992). 2007; 96:644-647.

60. Pritchard CC, Kroh E, Wood B, Arroyo JD, Dougherty KJ, Miyaji MM, Tait JF and Tewari M. Blood cell origin of circulating microRNAs: a cautionary note for cancer biomarker studies. Cancer Prev Res (Phila). 2011. 
61. Yao G, Yin M, Lian J, Tian H, Liu L, Li X and Sun F. MicroRNA-224 is involved in transforming growth factorbeta-mediated mouse granulosa cell proliferation and granulosa cell function by targeting Smad4. Molecular endocrinology (Baltimore, Md). 2010; 24:540-551.

62. An F, Olaru AV, Mezey E, Xie Q, Li L, Piontek KB and Selaru FM. MicroRNA-224 Induces G1/S Checkpoint Release in Liver Cancer. Journal of clinical medicine. 2015; 4:1713-1728.

63. Chen W, Fan XM, Mao L, Zhang JY, Li J, Wu JZ and Tang JH. MicroRNA-224: as a potential target for miR-based therapy of cancer. Tumour biology. 2015; 36:6645-6652.

64. Fu H, He HC, Han ZD, Wan YP, Luo HW, Huang YQ, Cai C, Liang YX, Dai QS, Jiang FN and Zhong WD. MicroRNA-224 and its target CAMKK2 synergistically influence tumor progression and patient prognosis in prostate cancer. Tumour biology. 2015; 36:1983-1991.

65. Liu Y, Wu C, Wang Y, Wen S, Wang J, Chen Z, He Q and Feng D. Expression of miR-224, miR-145, and their putative target ADAM17 in hepatocellular carcinoma. Acta biochimica et biophysica Sinica. 2014; 46:720-722.

66. Li Q, Ding C, Chen C, Zhang Z, Xiao H, Xie F, Lei L, Chen Y, Mao B, Jiang M, Li J, Wang D and Wang G. miR-224 promotion of cell migration and invasion by targeting Homeobox D 10 gene in human hepatocellular carcinoma. Journal of gastroenterology and hepatology. 2014; 29:835-842.

67. Huang L, Dai T, Lin X, Zhao X, Chen X, Wang C, Li X, Shen $\mathrm{H}$ and Wang X. MicroRNA-224 targets RKIP to control cell invasion and expression of metastasis genes in human breast cancer cells. Biochemical and biophysical research communications. 2012; 425:127-133.

68. Wang Y, Lee AT, Ma JZ, Wang J, Ren J, Yang Y, Tantoso E, Li KB, Ooi LL, Tan P and Lee CG. Profiling microRNA expression in hepatocellular carcinoma reveals microRNA-224 up-regulation and apoptosis inhibitor-5 as a microRNA-224-specific target. The Journal of biological chemistry. 2008; 283:13205-13215.

69. Wang H, Zhu LJ, Yang YC, Wang ZX and Wang R. MiR-224 promotes the chemoresistance of human lung adenocarcinoma cells to cisplatin via regulating $\mathrm{G}(1) / \mathrm{S}$ transition and apoptosis by targeting p21(WAF1/CIP1). British journal of cancer. 2014; 111:339-354.

70. Zhao H, Bi T, Qu Z, Jiang J, Cui S and Wang Y. Expression of miR-224-5p is associated with the original cisplatin resistance of ovarian papillary serous carcinoma. Oncology reports. 2014; 32:1003-1012.

71. Mencia N, Selga E, Noe V and Ciudad CJ. Underexpression of miR-224 in methotrexate resistant human colon cancer cells. Biochemical pharmacology. 2011; 82:1572-1582.

72. Song G, Song G, Ni H, Gu L, Liu H, Chen B, He B, Pan Y, Wang S and Cho WC. Deregulated expression of miR-224 and its target gene: CD59 predicts outcome of diffuse large B-cell lymphoma patients treated with R-CHOP. Current cancer drug targets. 2014; 14:659-670.
73. Upraity S, Kazi S, Padul V and Shirsat NV. MiR224 expression increases radiation sensitivity of glioblastoma cells. Biochemical and biophysical research communications. 2014; 448:225-230.

74. Gyongyosi B, Vegh E, Jaray B, Szekely E, Fassan M, Bodoky G, Schaff Z and Kiss A. Pretreatment MicroRNA Level and Outcome in Sorafenib-treated Hepatocellular Carcinoma. The journal of histochemistry and cytochemistry. 2014; 62:547-555.

75. Roayaie S, Obeidat K, Sposito C, Mariani L, Bhoori S, Pellegrinelli A, Labow D, Llovet JM, Schwartz M and Mazzaferro V. Resection of hepatocellular cancer $</=2 \mathrm{~cm}$ : results from two Western centers. Hepatology (Baltimore, Md). 2013; 57:1426-1435.

76. Collier J and Sherman M. Screening for hepatocellular carcinoma. Hepatology (Baltimore, Md). 1998; 27:273-278.

77. Deyashiki Y, Nishioka Y, Takahashi K, Kosaka Y and Suzuki K. Evaluation of des-gamma-carboxy prothrombin as a marker protein of hepatocellular carcinoma. Cancer. 1989; 64:2546-2551.

78. Nakao A, Suzuki Y, Isshiki K, Kimura Y, Takeda S, Kishimoto W, Nonami T, Harada A and Takagi H. Clinical evaluation of plasma abnormal prothrombin (des-gamma-carboxy prothrombin) in hepatobiliary malignancies and other diseases. The American journal of gastroenterology. 1991; 86:62-66.

79. Lefrere JJ, Gozin D, Lerable J and Soulier JP. Des-gammacarboxyprothrombin assay in alcoholic cirrhotic patients with alpha-fetoprotein level slightly increased. Hepatology (Baltimore, Md). 1986; 6:1066-1067.

80. Hung CH, Hu TH, Lu SN, Kuo FY, Chen CH, Wang JH, Huang CM, Lee CM, Lin CY, Yen YH and Chiu YC. Circulating microRNAs as biomarkers for diagnosis of early hepatocellular carcinoma associated with hepatitis B virus. International journal of cancer. 2015.

81. Colli A, Fraquelli M, Casazza G, Massironi S, Colucci A, Conte D and Duca P. Accuracy of ultrasonography, spiral CT, magnetic resonance, and alpha-fetoprotein in diagnosing hepatocellular carcinoma: a systematic review. The American journal of gastroenterology. 2006; 101:513-523.

82. Kawata S, Murakami T, Kim T, Hori M, Federle MP, Kumano S, Sugihara E, Makino S, Nakamura H and Kudo M. Multidetector CT: diagnostic impact of slice thickness on detection of hypervascular hepatocellular carcinoma. AJR American journal of roentgenology. 2002; 179:61-66.

83. Akai H, Kiryu S, Matsuda I, Satou J, Takao H, Tajima T, Watanabe Y, Imamura H, Kokudo N, Akahane M and Ohtomo K. Detection of hepatocellular carcinoma by Gd-EOB-DTPA-enhanced liver MRI: comparison with triple phase 64 detector row helical CT. European journal of radiology. 2011; 80:310-315.

84. Takeshita N, Hoshino I, Mori M, Akutsu Y, Hanari N, Yoneyama Y, Ikeda N, Isozaki Y, Maruyama T, Akanuma N, Komatsu A, Jitsukawa M and Matsubara H. Serum 
microRNA expression profile: $\operatorname{miR}-1246$ as a novel diagnostic and prognostic biomarker for oesophageal squamous cell carcinoma. British journal of cancer. 2013; 108:644-652.

85. Li A, Yu J, Kim H, Wolfgang CL, Canto MI, Hruban RH and Goggins M. MicroRNA array analysis finds elevated serum miR-1290 accurately distinguishes patients with lowstage pancreatic cancer from healthy and disease controls. Clinical cancer research. 2013; 19:3600-3610.

86. Liu M, Liu J, Wang L, Wu H, Zhou C, Zhu H, Xu N and Xie Y. Association of serum microRNA expression in hepatocellular carcinomas treated with transarterial chemoembolization and patient survival. PloS one. 2014; 9:e109347.

87. Lin L, Lu B, Yu J, Liu W and Zhou A. Serum miR-224 as a biomarker for detection of hepatocellular carcinoma at early stage. Clinics and research in hepatology and gastroenterology. 2015.
88. Zhuang LP and Meng ZQ. Serum miR-224 reflects stage of hepatocellular carcinoma and predicts survival. BioMed research international. 2015; 2015:731781.

89. Liver Cancer Study Group of Japan: General Rules for the Clinical and Pathological Study of Primary Liver Cancer, 5th Japanese edition. Tokyo: Kanehara \& Co., Ltd., 2010.

90. Sobin LH, Gospodarowicz MK, Wittekind C. International Union Against Cancer (UICC) TNM Classification of Malignant Tumours. 7th ed. Wiley-Blackwell; 2009.

91. Livak KJ and Schmittgen TD. Analysis of relative gene expression data using real-time quantitative PCR and the 2(-Delta Delta C(T)) Method. Methods (San Diego, Calif). 2001; 25:402-408.

92. Pfaffl MW. A new mathematical model for relative quantification in real-time RT-PCR. Nucleic acids research. 2001; 29:e45. 